\title{
Reforma Educacional em Cabo Verde e a Internacionalização das Políticas Educacionais
}

\author{
Paulo Sérgio Graça Delgado ${ }^{1}$, \\ MarilâNDES Mól Ribeiro MELO²
}

\begin{abstract}
RESUMO
Neste artigo propomo-nos a analisar a primeira reforma educacional ocorrida em Cabo Verde, a Lei de Bases do Sistema Educativo de 1990, assim como o DecretoLegislativo $n^{\circ}$ 2/2010 de 7 de Maio de 2010, que altera algumas prerrogativas da primeira reforma. Antes, nos predispomos a analisar a Conferência de Jomtien e a de Dakar, porque partimos do pressuposto de que há um movimento que visa à internacionalização das políticas educacionais.
\end{abstract}

Palavras-chave: Sociologia da educação. Reformas educacionais. Organismos internacionais. Cabo Verde.

\section{Educational Reform in Cape Verde and the Internationalization of the Educational Politics}

\begin{abstract}
On this paper we intend to analyze the first educational reform that took place in Cape Verde (1990's Basic Law of the Education System) as well as the legislative decree $\mathrm{n}^{\circ}$ 2/2010 of May 07th, 2010 amending some prerogatives on the first reform. With the assumption that there is a movement towards the internationalization of

1 Mestrando em Sociologia e História da Educação no Programa de Pós-Graduação em Educação na Universidade Federal de Santa Catarina (UFSC), Brasil. paulodelgado_9@ hotmail.com

2 Doutora em Educação e Professora do Instituto Federal Catarinense, Brasil. marilandesmel@ bol.com.br
\end{abstract}


educational politics, our analysis departs with an account of the Jomtien and Dakar Conferences.

Keyword: Sociology of education. Educational reforms. International organizations. Cape Verde.

\section{INTRODUÇÃo}

Considerando que este artigo tem por finalidade analisar a primeira reforma educacional ocorrida em Cabo Verde, a Lei de Bases do Sistema Educativo de 1990 e o Decreto-Legislativo $n^{\circ}$ 2/2010, tornase necessário discorrermos, mesmo que brevemente, sobre o país em questão. Cabo Verde é um arquipélago localizado na costa ocidental Africana. O país é constituído por dez (10) ilhas, das quais nove (9) são habitadas. Essas ilhas cobrem um total de 4000 (quatro mil) quilômetros quadrados.

Cabo Verde conquistou a sua independência em 1975, depois de anos de luta armada ${ }^{3}$. Fernandes (2007), ao desenvolver o estudo "Guiné - Bissau e Cabo Verde: da unidade à separação", entende as ideias de autonomia e independência após a Segunda Guerra Mundial como um fenômeno universal. Este pesquisador afirma que:

É nesta conjuntura política e de uma nova ordem política e de relações internacionais que na África sob dominação portuguesa emergiram movimentos nacionalistas cujo objectivo último era a independência das colónias. Apoiados embora tardiamente pela O.N.U (Organização das Nações Unidas), os movimentos nacionalistas das colónias portuguesas empreenderam uma luta, que do seu aspecto meramente politico transformou numa luta armada que teve o seu reflexo na própria metrópole, pois indirectamente acabou por derrubar o próprio regime que negava a independência às colónias e como consequência a independência das próprias colónias (FERNANDES, 2007, p. 10) ${ }^{4}$.

3 Devemos salientar que essa luta armada não aconteceu em solo cabo-verdiano, mas sim na Guiné-Bissau.

4 O texto foi mantido na versão original: português de Portugal. 
Já em 1991 houve a abertura política com a instituição do multipartidarismo no arquipélago. Em razão disso, nesse mesmo ano, pela primeira vez os cabo-verdianos foram às urnas.

No nosso estudo, partimos do pressuposto de que há um movimento de internacionalização das políticas educacionais. No período aqui pesquisado, esse movimento pode ser observado por meio da Conferência de Jomtien. Pensamos que a reforma educacional em Cabo Verde foi uma materialização dos pressupostos dessa conferência. Na nossa análise, notamos que há correspondência entre a conferência e a reforma no sistema de ensino cabo-verdiano.

Para a realização desta pesquisa nos baseamos em recursos metodológicos como o estudo bibliográfico, mas, sobretudo, a análise documental. Esta metodologia nos permitiu fazer uma análise dos documentos que regem o ensino em Cabo Verde, a saber, a Lei de Bases de Cabo Verde de 1990 e o Decreto-Legislativo de 2010. Segundo Triviños (2006, p. 111), “a análise documental [...] fornece ao investigador a possibilidade de reunir uma grande quantidade de informações sobre leis estaduais de educação, processos e condições escolares". A análise documental permitiu-nos perceber que, com o objetivo de ampliar e democratizar a educação, as diretrizes educacionais levadas a cabo pela reforma têm o propósito de fazer com que a educação nacional tome outro rumo, diferente do que até então estava em vigência no arquipélago.

\section{Educação e Organismos Internacionais ${ }^{5}$}

Neste tópico iremos nos debruçar sobre dois documentos resultados de conferências: referimo-nos à Conferência Mundial de Educação para Todos (1990) e à Conferência de Dakar - educação para

5 Neste artigo, referindo-nos a organismos internacionais, focamo-nos no Banco Mundial. No entanto, sabemos que há outras organizações supranacionais que buscam formular agendas de reformas educacionais e que entre eles, podem ser encontradas diferenças políticas. 
todos (2000). Do nosso ponto de vista, eles foram marco para a educação mundial devido à importância e influência que tiveram e/ou têm. Pensamos que esses dois documentos são importantes, porque foram os expoentes ou os guias para as reformas nas políticas educacionais que se verificaram a partir do período já demarcado. Abriram espaço para que fossem debatidas novas prioridades educacionais, servindo como suporte aos diversos países que se propuseram, desde então, a efetuar reformas educacionais nacionais.

Devemos ter em conta que as políticas educacionais contidas nesses documentos, preparados pelas organizações internacionais, se colocam em meio a "demandas por democratização do acesso inspiradas na ideia de que a educação é promotora de justiça - e a realidade dos sistemas educacionais, frequentemente considerados copartícipes das injustiças sociais" (VALLE, 2010, p. 39). Portanto, por meio desses documentos, pode-se perceber uma tentativa de democratização, sobretudo da educação básica, assim como uma tentativa de universalizá-la.

Esses são documentos políticos e sua pretensão é ter uma ampla difusão. Em virtude disso, acabam por apresentar um caráter generalista porque almejam certa homogeneização, desconsiderando o fato de que se dirigem a públicos heterogêneos. Assim, funcionam como um todo que quer juntar partes que, por natureza, não são iguais. Esses documentos carregam consigo um poder simbólico que lhes confere legitimidade perante os demais; isso ocorre porque se trata de documentos preparados por organizações que possuem legitimidade em esferas sociais e sabe-se que "'os sistemas simbólicos' distinguemse fundamentalmente conforme sejam produzidos" (BOURDIEU, 1989 , p. 12). O fato de esses documentos serem elaborados por "especialistas" da área educacional, lhes confere a legitimidade que necessitam para que sejam considerados parâmetros importantes no campo educacional. 
Nesse sentido, através desses documentos, estabelece-se uma relação de poder entre os que estão por dentro da sua organização e os outros que por norma, 'devem' acatá-los, ainda que com ressalvas, porque o poder simbólico define-se na relação entre quem exerce o poder e os que estão a ele sujeitos (BOURDIEU, 1989). Nota-se neles um poder simbólico que coloca em movimento um processo global, colocado em pauta por meio da importância atribuída à educação - sobretudo a educação básica. As Conferências anteriormente mencionadas foram realizadas depois do "Consenso de Washington" que foi realizado em 1989. Isto é, aconteceram em um período no qual políticas neoliberais estavam sendo disseminadas, sobretudo para países em desenvolvimento ${ }^{6}$.

Tendo em conta que o nosso marco temporal é de 1990 a 2010, não há como iniciar a nossa análise sobre as políticas educacionais, sem trazer para o debate a Conferência Mundial de Educação para Todos, realizada em Jomtien, na Tailândia, em 1990. Ela contém dez (10) artigos $^{7}$, sendo esses os pontos principais dessa conferência. O primeiro artigo é o lema da declaração, refere-se à "Satisfação das Necessidades Básicas de Aprendizagem", isto é, todos devem ter condições de satisfazer as suas necessidades básicas de aprendizagem como leitura, escrita, valores, entre outros. Nesse sentido, segundo esta declaração, a educação básica não tem finalidade em si mesma, sendo considerada um suporte que proporcionará novas capacitações. Outro objetivo da Conferência Mundial de Educação para todos é a universalização do acesso à educação e a promoção da equidade. Para que isso aconteça, de acordo com o documento, é necessário melhorar a qualidade da educação. Isso requer mais ênfase sobre a aprendizagem, fazendo o possível para que se reduzam as desigualdades, sobretudo em relação ao acesso das mulheres à educação.

\footnotetext{
6 Algumas instituições que organizaram as Conferências, como o Banco Mundial, participaram também do "Consenso de Washington".

7 Aqui no trabalho, não abordaremos os dez artigos de maneira aprofundada.
} 
Na declaração há um alerta, no sentido de que, para que haja a satisfação das necessidades básicas de aprendizagem é preciso fortalecer alianças internacionais por meio da angariação de um maior volume de recursos destinados à educação básica. Essas alianças podem ser nacionais, com vários setores tais como o privado, as comunidades locais, as famílias e Organizações não governamentais (ONGs); isto para que se possa obter recursos públicos, privados e voluntários.

Passados dez anos da Conferência de Jomtien foi realizada a Conferência de Dakar, que ocorreu entre os dias 26 e 28 de abril de 2000. Nela foram analisadas e debatidas as consequências da Conferência de Jomtien, tentando perceber em que aspectos tinha-se avançado, assim como instituir novos desafios para a educação. Podemos dizer que dessa Conferência saíram os grandes desafios educacionais para o início do novo milênio.

Assim, sob o lema "Educação para Todos", estabeleceramse alguns objetivos a serem atingidos. Sem entrarmos em cada um dos objetivos, percebe-se neles um olhar atento tanto para a criança pequena, quanto para a diminuição do analfabetismo. Notamos que nos objetivos traçados há uma grande ênfase na questão do gênero, em uma tentativa de proporcionar maior igualdade nesse quesito no campo educacional. Nesse sentido, cada governo deve tomar medidas para que as mulheres tenham mais acesso à educação.

Para que esses objetivos se tornem realidade, segundo o documento, é primordial ter vontade política tanto nacional como internacional, assim como uma participação mais ativa da sociedade nos rumos do desenvolvimento da educação. Dessa forma, um sistemático monitoramento do avanço de tais objetivos se torna indispensável.

Nesse processo, as organizações internacionais desempenham um papel fundamental, visto que elas disponibilizam recursos 
para que esses objetivos sejam alcançados, elaborando estratégias para atingi-los. Para isso indicam que é necessário aumentar o financiamento para a educação, sobretudo à educação básica, assim como ter um papel regulador das metas estipuladas. Ou seja, nesse documento perspectivou-se uma grande articulação entre os governos e as organizações internacionais.

\section{A Internacionalização das Políticas Educacionais}

Pretendemos explicitar aqui o que entendemos por políticas educacionais e mostrar como elas estão sendo influenciadas por decisões que são tomadas num contexto mais geral. Segundo Akkari (2011, p. 12), "uma política educacional é um conjunto de decisões tomadas antecipadamente, para indicar as expectativas e orientações da sociedade em relação à escola". As políticas educacionais trazem consigo um conjunto de medidas que deverão ser implementadas no campo educacional. Essas medidas são estabelecidas tendo em conta os objetivos propostos para um determinado período.

Nas últimas décadas, muito em virtude das decisões tomadas nas conferências abordadas anteriormente, notamos uma crescente inserção de organismos internacionais no campo educacional, não só como financiadores das políticas, mas também direcionando as leis educacionais dos países. Um exemplo é o Banco Mundial. Na nossa perspectiva está em curso um processo de internacionalização das políticas educacionais, com as agências internacionais fornecendo orientações (AKKARI, 2011).

Constata-se que, hoje em dia, o campo educacional tem sofrido influência dessas organizações. Morosini (2006, p. 109) assinala que "é a partir da década de 1990, com o processo de globalização, que a internacionalização da educação [...] vem se fortificando no panorama mundial"; desta maneira estamos diante de um "conceito 
relativamente jovem". Segundo Akkari (2011, p. 27), "as organizações internacionais, [...] gradualmente entram em jogo nas políticas nacionais de educação, colocando em questão o papel dos atores históricos em educação: o Estado e a sociedade civil". Isso quer dizer que as organizações internacionais cada vez mais entram no campo educacional dos diferentes países não só financiando projetos, mas também orientando políticas educacionais, estipulando muitas vezes os objetivos que devem ser buscados. Essas organizações, de certo modo, revelam às Nações o que deve ser uma educação de qualidade e como devem alcançá-la. Com isso, não estamos dizendo que os Estados e a sociedade civil ficam inoperantes, mas vêem os papéis que desempenhavam no campo educacional sofrendo mudanças e isso, muitas vezes, tem como resultado o recuo do Estado nesse campo.

Akkari (2011) afirma que existem três tipos de influência dos organismos internacionais tanto em países desenvolvidos como nos emergentes: na concepção de políticas educacionais; na avaliação dos sistemas educativos e no financiamento. Esses três tipos de influências desencadeiam alterações no campo educacional de cada país, na medida em que a concepção de educação deixa de ser meramente endógena.

Não podemos abordar o papel das Organizações Internacionais nas políticas educacionais sem referenciarmos o Banco Mundial (BM)8: se antes de 1990, a relação entre o BM e a educação se restringia ao financiamento, a partir de 1990, "o Banco passa a elaborar novas diretrizes políticas para as décadas futuras" (FONSECA, 1995, p. 171). Como um dos organismos internacionais mais influentes, o BM passa a direcionar as políticas educacionais para a perspectiva que ele considera ser uma educação de qualidade.

8 Daqui para diante ao nos referirmos ao Banco Mundial usaremos a sigla BM. 
Quando Cabo Verde conquistou a independência ${ }^{9}$, precisava de equilíbrio. Este - o equilíbrio - não podia vir da metrópole, porque estava tentando se desvencilhar de Portugal - ao menos politicamente. Assim sendo, durante o processo de descolonização, "na ausência de uma metrópole que apontasse os rumos, o país viu-se, a partir daí, obrigado a atrair recursos junto aos parceiros internacionais que garantissem a sua estabilidade" (MONIZ apud MORAIS, 2009, p. 48). $\mathrm{O} \mathrm{BM}^{10}$ foi um dos parceiros que o arquipélago encontrou.

\section{Reformas Educacionais}

Atemo-nos neste tópico às reformas educacionais ocorridas em Cabo Verde. Na nossa perspectiva, reforma é um processo pelo qual se pretende renovar, inovar. O propósito é então estabelecer mudanças, tendo em conta os objetivos traçados. No caso educacional, reforma vem a ser as inovações ocorridas em nível conceitual, estrutural e curricular, entre outros aspectos, dependendo dos objetivos que se estabeleceram para o setor educacional e, para o país como um todo. Enfim, desenvolver uma reforma educacional supõe pensar previamente nas suas finalidades, tendo em conta os objetivos traçados.

Sendoa reformaum "objeto das relações sociais" (POPKEWITZ, 1997), a reforma de 1990 em Cabo Verde veio funcionar como uma divisora de águas, estabelecendo-se como uma virada histórica no campo educacional cabo-verdiano, a partir de relações sociais de outra ordem, diferentes das do período colonial, assim como do período de partido único no arquipélago.

Cabo Verde conquistou a independência em 1975, mas até 1991 havia um sistema de partido único. Somente em 1991 se

9 Para aprofundar o assunto sugerimos as seguintes abordagens; LOPES $(1996,2003)$.

10 A própria Lei de Bases do Sistema educativo (Lei $n^{\circ}$. 103/III/1990), que será trabalhada aqui, é resultado do projeto financiado pelo Banco Mundial, com consultoria da UNESCO - projeto denominado PARTEX (MORAIS, 2009). 
instalou o multipartidarismo no arquipélago. Podemos dizer que a reforma educacional de 1990 veio no bojo dessas mudanças de maior amplitude que ocorreram no país. Por isso afirmamos que a instituição da Lei de Bases do Sistema Educativo de 1990 veio funcionar como o início de uma nova era, que se queria na educação cabo-verdiana, pois esta reforma tinha um claro propósito: deixar para trás o sistema educacional ainda um tanto colonial.

Dessa forma, concordamos com Popkewitz (1997, p. 21) quando diz que "a reforma educacional não transmite meramente informações em novas práticas. Definida como parte das relações sociais de escolarização, a reforma pode ser considerada como ponto estratégico no qual ocorre a modernização das instituições". Assim sendo, a reforma pode ser tomada como uma tentativa de mudança ou mesmo de modernização do sistema educativo, na medida em que ela não faz apenas parte de um mero instituir "novas práticas", mas também promover o estabelecimento de novas 'relações sociais de poder' (POPKEWITZ, 1997).

\section{Reforma Educacional em Cabo Verde}

A educação em Cabo Verde antes da independência era desconectada da realidade do país e isso foi um dos grandes impulsos para que se elaborasse a primeira Lei de Bases. Na era colonial, a política educacional visava "a promoção dos valores culturais da metrópole e a criação de defensores da unidade da Pátria, não a identificação do cabo-verdiano com os seus próprios valores, hábitos ou costumes" (TOLENTINO apud MORAIS, 2009, p. 26). Depois da independência, a educação foi vista como a "salvadora da pátria", pois foi considerada cerne do desenvolvimento das ilhas, através da formação da sua gente. Isto é, para que Cabo Verde se desenvolvesse era necessário investir na educação, já que os recursos naturais eram 
inexistentes. Percebemos então que à educação foi atribuído um papel fundamental na formação do cabo-verdiano, sendo anunciada como instrumento primordial para o desenvolvimento do país. Seria então uma instância que deveria promover a construção e a modernização do arquipélago. A década de 1980, em virtude de várias conjunturas, propiciou a elaboração da Lei de Bases do Sistema Educativo de 1990. Segundo Morais (2009 p. 39-40):

[...] as sucessivas mudanças que ocorriam em Cabo Verde nos planos demográfico, econômico e social por um lado, e o fracasso do sistema de ensino evidenciado pelas más condições estruturais, fraca qualidade de ensino e uma deficiente estrutura de formação profissional por outro lado, reforçavam a necessidade de uma profunda alteração do sistema educativo vigente, para fazer frente às tais alterações.

O país estava passando por mudanças em diversos setores e a educação que até então era oferecida, não estava à altura dos desafios, necessitando-se assim urgentemente de uma educação que acompanhasse tais transformações.

\section{Lei de Bases do Sistema Educativo: \\ LeI No 103/III/90 DE 29 DE Dezembro}

Em Cabo Verde, no ano de 1990 ocorreu a primeira reforma educacional. Essa lei definiria tanto o funcionamento, como a organização do sistema educacional, quinze anos depois da conquista da independência. Vale lembrar que o ensino da época colonial tinha um legado elitista, extremamente "seletivo, discriminatório, inadaptado às necessidades do país e aos interesses das populações" (PEREIRA apud VARELA, 2013, p. 19). Dessa forma, como já foi mencionado, era necessário que se pensasse uma educação que fosse menos seletiva do que a anterior e voltada para a realidade nacional. 
A educação depois da independência tinha um papel crucial: fazer com que o cabo-verdiano se identificasse com o seu país, com a sua cultura. Assim, na era pós-colonial - sobretudo com o processo de democratização do país - era imprescindível que se tentasse colocar em prática uma educação que criasse no consciente do cabo-verdiano um sentimento de pertencimento para com a sua terra, assim como uma tentativa de se estabelecer uma sociedade mais justa. Nesse sentido, tanto a nacionalização como a democratização da educação foram consideradas requisitos indispensáveis para que houvesse a igualdade de oportunidades (AFONSO apud GAMBÔA, 2008). Como forma de colocar essa política em prática, com a Lei de Bases de 1990 houve a inclusão da disciplina 'Cultura cabo-verdiana' no currículo escolar. Com isso havia um propósito claro: formar cidadãos conhecedores da sua terra e preparados para participarem da construção, do desenvolvimento do seu país. Aqui podemos perceber uma relação entre o global e o local. Se por um lado percebe-se o propósito de se universalizar o ensino - tendência global - esta é feita tendo em conta particularidades do arquipélago. Neste caso, pensa-se essa universalização atrelando-a aos anseios do país. No caso, não só formar o cidadão, mas fazê-lo tendo em conta o meio no qual este está inserido. Ou seja, há esse caráter generalizante das medidas tomadas pelas organizações internacionais e estas, por sua vez, podem ser particularizadas, a partir do contexto onde serão inseridas.

A Lei de Bases de 1990, na nossa perspectiva, se enquadra nas reformas que fazem "parte de importantes transformações e rupturas que ocorrem a nível nacional e internacional" (POPKEWITZ, 1997, p. 205). Essa Lei faz parte de transformações internacionais porque ela veio com um conjunto de mudanças que se pretendeu levar a cabo no campo educacional em escala mundial. Lembrando que Cabo Verde apostou na educação como o motor para o desenvolvimento e, não possuindo condições para universalizar a educação nas ilhas, tornou- 
se imperativo acatar medidas em voga, como condição para que tivesse possibilidades financeiras de instituir a educação pretendida. Desse modo, o financiamento da educação está relacionado com a implantação de medidas que no plano internacional são tomadas. Estava-se no processo de abertura política em Cabo Verde e, tendo em conta que se trata de um país com parcos recursos financeiros, as organizações internacionais - como Banco Africano de Desenvolvimento e o Banco Mundial - se transformaram nas fontes financiadoras por excelência dos projetos que se queria implementar.

A instituição das políticas públicas em Cabo Verde, portanto, depende de financiamento externo e a condição para esse financiamento é haver projetos que vão ao encontro do que é decidido no âmbito internacional. Há certa dependência do país em questão para com os organismos internacionais, havendo, portanto, uma relação de poder entre eles. Percebemos então que o financiamento dessas políticas públicas contribui para o processo que chamamos de internacionalização das políticas educacionais.

Nacionalmente essa reforma faz parte das transformações que aconteceram no arquipélago depois da independência. A década de 1990 se configurou por mudanças de várias ordens em Cabo Verde, tanto em nível econômico, como político, por meio da instituição do multipartidarismo. Por isso concordamos com Popkewitz (1997, p. 144) quando, referindo-se às reformas contemporâneas, diz que "o realinhamento econômico é um motivo, mas ele está inter-relacionado com aspectos culturais e políticos".

O organograma a seguir nos ajuda a entender como ficou estruturado o sistema de ensino em Cabo Verde, com a Lei de Bases de 1990. 


\section{Figura 1 - Organograma do Sistema educativo CABo-verdiano}

COM A Lei de BAses de 90

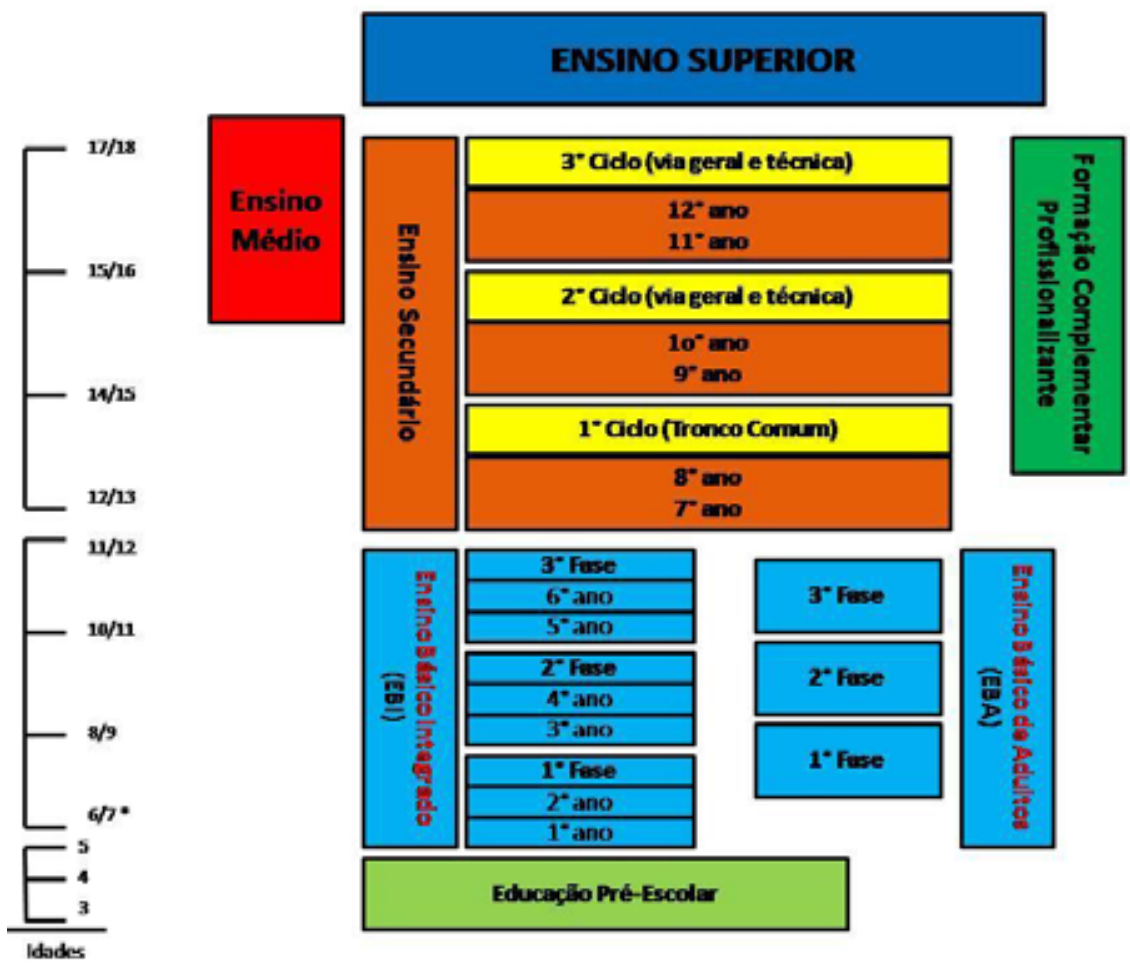

Fonte: Fonte: Plano Nacional de Acção de Educação para Todos (CABO VERDE, 2002, p. 6).

Devemos primeiramente dizer que, mesmo não dispensando intervenções locais no setor educacional, esta Lei de Bases deixa claro que ao Governo cabe elaborar, coordenar, executar e avaliar a política educativa cabo-verdiana: o governo toma para si o controle da educação nacional, fazendo com que haja centralização do controle e descentralização das responsabilidades (AKKARI, 2011, p. 122).

Percebemos pelo gráfico que a primeira etapa do sistema de ensino cabo-verdiano é a educação pré-escolar. Esta etapa se configura como uma educação complementar àquela oferecida pela família. Ela é de frequência facultativa, destinada às crianças dos três anos até a 
idade do ingresso no ensino básico11. Segundo a Lei de Bases de 1990, a educação pré-escolar está relacionada com a proteção da infância, visando o desenvolvimento da criança, assim como a preparação para o seu ingresso no sistema escolar12. Entre os objetivos podemos elencar a socialização da criança ${ }^{13}$, assim como a sua estabilidade afetiva ${ }^{14}$.

A educação escolar se subdivide em cinco níveis, a saber: ensino básico, secundário, médio, superior e modalidades especiais. O ensino básico é obrigatório e universal. Neste quesito, a Lei vai ao encontro do que foi proposto pela declaração de Jomtien, que é a universalização do ensino básico e a satisfação das necessidades básicas de aprendizagem. Ele abrange um total de seis anos, estando organizado em três fases de dois anos cada, sendo ministrado por um único professor.

O objetivo do ensino básico é favorecer a aquisição de conhecimento $^{15}$, o desenvolvimento de criatividade ${ }^{16}$, hábitos e atitudes ${ }^{17}$ que contribuam para a inserção do aluno na sociedade, assim como para despertar o interesse pelas profissões ${ }^{18}$. O plano de estudo deste nível de ensino é composto por quatro grandes áreas curriculares: Língua Portuguesa, Ciências Integradas (História, Ciências da Natureza e Geografia), Matemática e Expressões. Nas primeiras duas fases a área de expressões está dividida em expressão musical, expressão plástica, assim como físico-motora.

O ensino secundário tem a mesma duração - seis anos - e organização que o ensino básico. Está organizado em três ciclos: o primeiro de tronco comum, o segundo e o terceiro com duas vias,

\footnotetext{
11 Artigo $13 \S 2$.

12 Artigo $13 \S 1$.

13 Artigo $14 \S \mathrm{d}$

14 Artigo 14 §c.

15 Artigo $19 \S$ a.

16 Artigo 19 §d.

17 Artigo $19 \S \mathrm{h}$

18 Artigo 19 \$g.
} 
uma geral e outra técnica ${ }^{19}$. Entre os objetivos podemos destacar a aquisição de conhecimentos humanísticos, científicos e técnicos com os olhos postos em uma vida ativa, assim como o domínio da língua Portuguesa e o ensino de línguas estrangeiras ${ }^{20}$.

O ensino médio é de natureza profissionalizante cujo objetivoé a formação de quadros médios em domínios específicos de conhecimento (art. 28). Ele tem a duração de pelo menos três anos para os que ingressarem nesse nível de ensino com o décimo ano de escolaridade ${ }^{21}$. Para os que ingressarem com o décimo segundo ano - isto é, com o ensino secundário completo - o curso deverá ser de um ano ${ }^{22}$.

A reforma educacional 'dividiu' o ensino superior ${ }^{23}$ em ensino universitário e ensino politécnico ${ }^{24}$. O primeiro procura assegurar "uma sólida preparação científica e cultural e proporcionar uma formação técnica que habilite para o exercício de actividades profissionais e culturais e fomente o desenvolvimento das capacidades de concepção, de inovação e de análise crítica" (Art. 31 § 2). Por outro lado, o ensino politécnico procura "proporcionar uma sólida formação cultural e técnica de nível superior" (Art. $31 \S 2$ ). Dos objetivos deste nível de ensino podemos destacar o incentivo à pesquisa ${ }^{25}$, a formação em diferentes áreas de conhecimento ${ }^{26}$ e o desenvolvimento do espírito crítico nos estudantes ${ }^{27}$.

19 Artigo 23.

20 Artigo 22.

21 Artigo $30 \S 1$.

22 Artigo $30 \S 3$.

23 Bacharel, licenciado, mestre e doutor são os graus acadêmicos conferidos pelo ensino superior na Lei de Bases de 90 (art. 33 § 1). Em relação ao decreto-lei de 2010 percebe-se que há a supressão do bacharelato, sendo este uma das poucas mudanças que há nesse nível de ensino nos dois documentos.

24 Artigo $31 \S 1$.

25 Artigo $32 \S \mathrm{d}$.

26 Artigo $32 \S b$

27 Artigo $32 \S$ a. 
Já modalidades especiais referem-se à educação especial, ensino à distância ${ }^{28}$, ensino de adultos assim como de comunidades cabo-verdianas no estrangeiro ${ }^{29}$. A educação extraescolar refere-se a atividades de alfabetização, formação profissional, entre outras ${ }^{30}$.

\section{Decreto-Legislativo № 2/2010 de 7 de Maio de $2010^{31}$}

O Decreto-legislativo nº 2/2010 revê as Bases do sistema educativo, que foram anteriormente aprovadas pela Lei 103/III/90, de 29 de Dezembro. Esse novo decreto assenta-se na justificativa de que o crescimento das demandas exige uma adequação do setor educacional com vista ao desenvolvimento do país. Para isso "a qualificação do capital humano constitui um recurso fundamental" (CABO VERDE, 2010, p. 2). A Teoria do Capital humano remonta às bases teóricas desenvolvidas Theodore W. Schultz, nos anos 1960, que defende a compreensão da educação como um investimento. Schultz define seu pensamento da seguinte forma:

[...] a característica distintiva do capital humano é a de que é parte do homem. É humano porquanto se acha configurado no homem, e é capital porque é uma fonte de satisfações futuras, ou de futuros rendimentos, ou ambas as coisas. Onde os homens sejam pessoas livres, o capital humano não é um ativo negociável, no sentido de que possa ser vendido. Pode, sem dúvida, ser adquirido, não como um elemento de ativo, que se adquire no mercado, mas por intermédio de um investimento no próprio indivíduo. Segue-se que nenhuma pessoa pode separarse a si mesma do capital humano que possui. Tem de acompanhar, sempre, o seu capital humano, quer o sirva na produção ou no consumo (SCHULTZ, 1973, p. 53).

28 Para a realidade cabo-verdiana da época, este modelo de ensino parece-nos muito difícil para não dizer impossível, em virtude da falta de condições de propiciar tal modalidade

29 Artigos 44, 47, 48, 49.

30 Artigo 50 § a; $50 \S \mathrm{b}$.

31 Devemos afirmar que aqui nos focamos no Decreto-lei em si e não na transposição ou na implementação do que consta no decreto-lei. Dizemos isso porque a implementação da nova estrutura do sistema de ensino cabo-verdiano não foi efetivada em 2010. 
Tendo isso em conta, podemos dizer que foca-se na produtividade individual como requisito para o desenvolvimento nacional. Devemos dizer que a sociologia da educação nos adverte que o capital humano ignora que o rendimento escolar depende do capital cultural que é investido pela família, do mesmo modo, o rendimento econômico e social do certificado é também "produto" do capital social (BOURDIEU, 1998).

O decreto-legislativo de 2010 está pautado na tentativa de modernizaçãodosistemaeducativo cabo-verdiano. Noreferidodecreto, entende-se currículo nacional como "conjunto das aprendizagens a desenvolver pelos alunos que freqüentam o sistema e os subsistemas educativos" o que se concretizará "através da definição de planos de estudo elaborados com base em matérias curriculares" (Art. $15 \S 2$ ). Essa percepção de currículo foi criticada por Varela (2013), aludindo que esta é uma ideia redutora e prescritiva do currículo em que o mesmo seria um mero "plano de estudos", não sendo, portanto, um mecanismo onde se encontra "saber e poder, representação e domínio, discurso e regulação" (PACHECO apud GAMBÔA, 2008, p. 22), ou ainda um "espaço de produção de cultura" (LIBÂNEO apud VALLE, 2014, p. 88). Com este decreto-lei, a estrutura do sistema de ensino cabo-verdiano ficou da seguinte forma: 


\section{Figura 2 - Organograma do sistema educativo de Cabo Verde COM O DeCRETO-LEI DE 2010}



Fonte: Elaborado pelo autor com base nas informações contidas no Decreto-lei n 2/2010

Com este Decreto-lei os subsistemas pouco se modificaram, compreendendo a educação pré-escolar, escolar e extraescolar. O sistema educativo incorporou a formação técnico-profissional articulando-se ao sistema nacional de formação profissional. A grande novidade desse decreto-lei diz respeito tanto à estrutura do sistema educativo quanto à obrigatoriedade.

Oingresso na pré-escola passou dos três (3) para quatro (4) anos, caracterizando, portanto, um ano a menos na educação infantil. $\mathrm{O}$ fato de se diminuir um ano na educação infantil, além de ser facultativo, pode ser visto de duas formas: (1) o Estado cabo-verdiano, ainda, não vê a educação infantil como uma etapa extremamente importante no processo de desenvolvimento da criança, pelas vivências que pode proporcionar, podendo melhorar o seu desempenho nas próximas 
etapas do ensino; (2) significa que a socialização educacional se prolonga no espaço familiar.

Em relação à estrutura, o ensino básico passou a ser de oito anos, compreendendo três "ciclos sequenciais" em que o primeiro é de quatro anos e os outros dois ciclos de dois anos cada ${ }^{32}$. No primeiro ciclo, o ensino é globalizante e de responsabilidade de um único professor, que pode ser auxiliado em relação às áreas especializadas ${ }^{33}$. No segundo ciclo o ensino já é organizado por áreas interdisciplinares, neste caso, o regime é de docente por área ${ }^{34}$. Já o terceiro ciclo tem um plano curricular unificado que deverá integrar as diversas áreas ${ }^{35}$. Nesse caso há "um docente por disciplina ou grupos de disciplinas" (art. 28. 1. c). Assim sendo, cada ciclo terá o papel de aprimorar, aprofundar, completar o ciclo anterior ${ }^{36}$.

Essa mudança estrutural noensino básico trouxe consequências também estruturais para o ensino secundário. Este passa a ser de quatro anos, compreendendo dois ciclos de dois anos cada. $\mathrm{O} 1^{\circ}$ ciclo - $9^{\circ}$ e $10^{\circ}$ anos - tem uma via geral, que constitui um ciclo de consolidação do ensino básico e de orientação vocacional. O segundo ciclo, que corresponde ao $11^{\circ}$ e $12^{\circ}$ anos de escolaridade, tem uma "via de ensino geral e outra técnica" (art. 26. 2. b).

A obrigatoriedade e a universalidade da educação passaram a abranger o $10^{\circ}$ ano de escolaridade, ou seja, até o primeiro ciclo do ensino secundário. No entanto, a gratuidade compreende apenas o ensino básico, isto é, tem duração de oito anos. Deste modo, percebese que há um hiato entre a gratuidade e a obrigatoriedade, tendo em conta que o nono e o décimo anos, apesar de serem obrigatórios, não são gratuitos, segundo o decreto-lei.

32 Artigo 23.

33 Artigo $23 \S$ a

34 Artigo $23 \S b$

35 Artigo $23 \S \mathrm{c}$

36 Artigo $23 \S 2$. 


\section{Conclusão}

Percebemos que as conferências trabalhadas anteriormente funcionaram como espelho para as reformas educacionais em Cabo Verde, sobretudo em relação à universalização da educação primária. A década de 90 em Cabo Verde foi marcada pelo esforço em expandir a educação primária, de modo que os cabo-verdianos pudessem adquirir aprendizagens básicas que lhes permitissem ajudar no desenvolvimento do país. Esta era uma forma de combater, por exemplo, a alta porcentagem de analfabetos que havia em Cabo Verde na época.

As aprendizagens básicas incluem o "aprender a conhecer". Neste caso, aprender a conhecer a realidade cabo-verdiana, o que não acontecia antes da independência. Nesse sentido, pode-se dizer que a satisfação das necessidades básicas de aprendizagem foi o foco da reforma educacional de 1990, tendo em conta que o país queria democratizar o ensino, fazendo com que os cabo-verdianos tivessem mais acesso a ele. Entende-se, portanto, que a universalização do acesso à educação era um objetivo da reforma, tendo em conta que só se combate o analfabetismo universalizando e democratizando o acesso à educação. Desse modo, podemos dizer que a reforma educacional estava alinhada com a conferência de Jomtien, já que a satisfação das necessidades básicas de aprendizagem era seu lema.

Para que se pudesse atingir os objetivos propostos para o sistema educacional, Cabo Verde teve que contar com a ajuda externa, porque não tinha condições de, sozinho, alcançá-los. Nesse sentido, o Banco Africano de Desenvolvimento (BAD), por exemplo, foi um grande aliado. Novamente, percebe-se que Cabo Verde seguiu a ideia das declarações, ao procurar alianças internacionais para implementar sua política educacional. Aliás, como mostramos anteriormente, o financiamento a países como Cabo Verde depende do quanto estes 
estão dispostos a implementar políticas públicas que as organizações desejam que acatem. Há, portanto, um jogo de forças que acaba por contribuir para a internacionalização das políticas educacionais.

Com a Lei de Bases de 1990 e o Decreto-Legislativo de 2010, notamos dois momentos na educação cabo-verdiana: no primeiro, notase o objetivo de fazer com que a educação em Cabo Verde possibilite ao cabo-verdiano uma maior vinculação sentimental com o seu país. Para isso, no sistema educacional dever-se-ia abordar questões nacionais, visando evitar que a realidade local fosse desconhecida pelos nativos. Com o Decreto-lei de 2010, o movimento é outro: neste caso, tenta-se aprimorar o sistema educacional 'espelhando-se' no que acontece nesse campo no cenário global. O foco no capital humano é um exemplo desse movimento.

\section{REFERÊNCIAS}

AKKARI, Abdeljalil. Internacionalização das políticas educacionais: transformações e desafios. Petrópolis: Vozes, 2011.

BOURDIEU, P. O poder simbólico. Rio de Janeiro: Ed. Bertrand, 1989.

BOURDIEU, Pierre; NOGUEIRA, Maria Alice; CATANI, Afrânio Mendes (Org.). Escritos de educação. Petrópolis: Vozes, 1998.

CABO VERDE. Decreto-Legislativo n² 2/2010 de 7 de maio de 2010. Cabo Verde, 2010.

CABO VERDE. Lei de Bases do Sistema Educativo: Lei ${ }^{\circ}$ 103/III/90 de 29 de dezembro de 1990. Cabo Verde, 1990.

CABO VERDE. Plano Nacional de Acção de Educação para Todos. Cabo Verde, 2002.

FERNANDES, Antero da Conceição Monteiro. Guiné - Bissau e Cabo Verde: da unidade à separação. Dissertação (Mestrado em Estudos Africanos) - Faculdade de Letras. Centro de Estudos Africanos, Universidade do Porto, Porto, 2007.

FONSECA, M. O Banco Mundial e a educação: reflexões sobre o caso brasileiro. In: GENTILLI, Pablo (Org.). Pedagogia da exclusão. Petrópolis: Vozes, 1995. p. 169-195. 
GAMBÔA, Cecília Monteiro Fernandes. A formação educativa e o currículo para o ensino secundário em Cabo Verde (1990/2005). 2008. 104 p. Dissertação (Mestrado em Educação) - Universidade Federal de Santa Catarina, Florianópolis.

LOPES, José Vicente. Cabo Verde, as causas da independência. Praia: Spleen, 2003.

LOPES, José Vicente. Os bastidores da independência de Cabo Verde. Praia: Centro Cultural português, 1996.

MORAIS, J. J. M. Cabo Verde: um projeto de país e a ideologia de educação como estratégia para o desenvolvimento: estudo da constituição do ensino técnico. 2009. Dissertação (Mestrado em Educação) - Universidade Federal do Paraná, Curitiba, 2009.

MOROSINI, Marília Costa. Estado do conhecimento sobre internacionalização da educação superior: conceitos e práticas. Educar, Curitiba, n. 28, p. 107-124, 2006.

POPKEWITZ, Thomas S. Reforma educacional: uma política sociológica: poder e conhecimento. Porto Alegre: Artes Médicas, 1997.

SCHULTZ, Theodore W. O capital humano: investimentos em educação e pesquisa. 2. ed. Zahar Editores, 1973.

TRIVIÑOS, N. S. Introdução a pesquisa em ciências sociais: a pesquisa qualificativa em educação. 5. ed. São Paulo: Atlas, 2006.

VALLE, Ione Ribeiro. Justiça na escola: das desigualdades justas à igualdade sem adjetivos!. In: VALLE, Ione Ribeiro; SILVA, Vera Lúcia Gaspar da; DAROS, Maria das Dores (Org.). Educação Escolar e Justiça Social. Florianópolis: Nup, 2010. p. 19-48.

VALLE, Ione Ribeiro. Sociologia da educação: currículo e saberes escolares. 2. ed. Florianópolis: Ed. da UFSC, 2014. 114 p. (Coleção Didática).

VARELA, B. L. A evolução do ensino superior público em Cabo Verde: da criação do curso de formação de professores do ensino secundário à instalação da Universidade Pública. Praia. Edições UNICV. 2013. 